\title{
Gas Exchange by Intratracheal Insufflation in a Ventilatory Failure Dog Model
}

\author{
Noam Gavriely, David Eckmann, and James B. Grotberg \\ Department of Anesthesia, Northwestern University Medical School, Chicago, Illinois 60611; Biomedical Engineering Department, \\ McCormick School of Engineering and Applied Science, Northwestern University, Evanston, Illinois 60208; and Department of \\ Physiology and Biophysics, Faculty of Medicine and the Rappaport Family Institute for Research in the Medical Sciences, \\ Technion-Israel Institute of Technology, Haifa, Israel
}

\begin{abstract}
Respiratory insufficiency patients who need only partial ventilatory support are, nevertheless, intubated and connected to a respirator. In search of a partial respiratory assistance method we evaluated the gas exchange, mechanisms, and hemodynamic effects of intratracheal insufflation (ITI) via a narrow $(0.2-\mathrm{cm})$ catheter. The effects of flow rate (0.05-0.2 liter/min per $\mathbf{~ k g ) , ~}$ catheter tip position (carina, bronchus, and trachea), and superimposed chest vibration at $22 \mathrm{~Hz}$ were studied in seven anesthetized and partially paralyzed dogs. ITI in the carina induced $\mathrm{CO}_{2}$ removal $\left(\dot{\mathrm{V}}_{\mathrm{CO}_{2}}\right)$ of $48 \pm 16 \mathrm{ml} / \mathrm{min}$ in the periods between breaths, which was $39 \%$ of the control $\mathrm{V}_{\mathrm{CO}_{2}} \cdot \mathrm{CO}_{2}$ removal rates between breaths with ITI in a bronchus and in the trachea were 63 and $28 \%$ of control, respectively $(P<0.05)$. ITI at 0.15-0.2 liter / $\mathrm{min}$ per $\mathrm{kg}$ augmented total $\mathrm{V}_{\mathrm{CO}_{2}}$ by $>50 \%$ over control $(P<0.05)$ and decreased $\mathrm{Pa}_{\mathrm{CO}_{2}}$ by $10 \%(P<0.05)$ despite a $28 \%$ fall in $\dot{V}_{E}$ and $32 \%$ lower work of breathing ( $P$ $<0.05$ ). Adding vibration to ITI at $0.15 \mathrm{liter} / \mathrm{min}$ per $\mathrm{kg}$ induced $\dot{\mathrm{V}} \mathrm{CO}_{2}$ of $162 \pm 34 \mathrm{ml} / \mathrm{min}$, which was significantly greater than control, while $\mathrm{Pa}_{\mathrm{CO}_{2}}$ fell from $69 \pm 24$ to $47 \pm 6 \mathrm{mmHg}$ ( $P$ $<0.05)$, despite complete cessation of spontaneous breathing. ITI with or without vibration did not cause any hemodynamic changes, except for a fall in the shunt fraction from $14.6 \pm 9.9 \%$ to $\mathbf{5 . 8} \pm \mathbf{2 . 8 \%}$ with vibration. Thus, ITI at low flow rates can support respiration with no hemodynamic side effects. Adding chest vibration further enhances gas exchange and can provide total ventilation. (J. Clin. Invest. 1992. 90:2376-2383.) Key words: artificial ventilation • vibration • respiratory failure
\end{abstract}

\section{Introduction}

Some respiratory failure patients are predominantly inflicted with ventilatory insufficiency. These patients usually have rudimentary spontaneous breathing, but are unable to support their respiratory metabolic needs and often require prolonged artificial ventilation. The etiology is diverse; e.g., traumatic cervical cord transection, or stable or progressive neuromuscular disorders are among the more frequent causes. Currently, in all the patients who need mechanical ventilation, endotracheal

Address correspondence to Noam Gavriely, M.D., D.Sc., Head, Pulmonary Physiology Unit, Faculty of Medicine, Technion-Israel Institute of Technology, PO Box 9697, Haifa, Israel. 1992.

Received for publication 10 March 1992 and in revised form 9 July

J. Clin. Invest.

(C) The American Society for Clinical Investigation, Inc.

$0021-9738 / 92 / 12 / 2376 / 08 \quad \$ 2.00$

Volume 90, December 1992, 2376-2383 intubation (ETT) ${ }^{1}$ (oral, nasal, or via tracheostomy) is performed and intermittent positive pressure ventilation is applied. These procedures are straightforward and guarantee adequate airway care and gas exchange. Nevertheless, side effects such as limitations on patients' ability to talk, swallow and cough effectively, tracheal irritation, pulmonary pressure trauma, hemodynamic interference, the cost of equipment, and the requirement for specialized personnel have stimulated investigators to search for alternatives.

Application of subatmospheric intermittent external pressure to the whole body or the chest wall by the iron lung or by a chest-abdomen cuirass at regular or high frequency rates was designed to increase alveolar ventilation without the need to access the airways $(1,2)$. The rocking bed method uses gravity to change intermittently transdiaphragmatic pressure and induce airway flow ( 3 ). The common intent of these methods is to improve ventilation without endotracheal intubation. In recent years, other alternative modes of ventilation have been proposed and studied in animals and patients. These methods include high frequency ventilation (4), constant flow ventilation at flow rates $>1.0 \mathrm{liter} / \mathrm{min}$ per $\mathrm{kg} \mathrm{(5),} \mathrm{and} \mathrm{high} \mathrm{fre-}$ quency jet ventilation (6). Such methods do not necessarily eliminate the need for endotracheal intubation and have not been demonstrated to provide a significant advantage over intermittent positive pressure ventilation (7).

Low flow (i.e., $<0.2$ liter $/ \mathrm{kg}$ per $\mathrm{min}$ ) intratracheal insufflation of air or $\mathrm{O}_{2}$ (ITI, TRIO) via a narrow catheter placed near the main carina was used in animal models of severe ventilatory failure with or without high frequency vibration of the chest wall or the whole body (8-11). These studies showed that low flow tracheal insufflation of oxygen, when used without external vibration, can sustain oxygenation during apnea, but cannot sufficiently remove $\mathrm{CO}_{2}$ from the lungs (10-11). Addition of external chest wall vibration at frequencies of $15-30 \mathrm{~Hz}$ and an amplitude of $0.2 \mathrm{~cm}$ to ITI improved alveolar ventilation, so that normal or low $\mathrm{Pa}_{\mathrm{CO}_{2}}$ levels were reached (8-9). Recently, ITI was used by Bergofsky and Hurewitz (12) in five patients and by Couser and Make (13) in five patients suffering from hypoventilation and $\mathrm{CO}_{2}$ retention. In both studies, an improvement of the efficiency of the ventilatory gas transport was found, manifested as an increased $\mathrm{CO}_{2}$ elimination, despite lower minute ventilation. While ITI still requires patient instrumentation with an endotracheal tube, the much smaller size of the tube and the use of constant, rather than intermit-

1. Abbreviations used in this paper: $\mathrm{Br}$., bronchi; ECG, electrocardiogram; ETT, endotracheal tube; ITI, intratracheal insufflation; $\dot{\mathrm{V}}_{\mathbf{A}}$, alveolar ventilation; $\dot{\mathrm{V}} \mathrm{CO}_{2}$, control carbon dioxide elimination rate; $\mathrm{V}_{\mathrm{D}}$ Bohr, Bohr dead space; $\dot{\mathrm{V}}_{\mathrm{E}}$, spontaneous breathing minute ventilation; VEI, ventilatory efficiency index; $\dot{\mathrm{V}}_{\mathrm{ITI}}$, ITI flow; $\dot{\mathrm{VO}}_{2}$, oxygen consumption rate; $\mathrm{V}_{\mathrm{T}}$, spontaneous tidal volume; $\mathrm{WI}$, inspiratory external work of breathing. 
tent flows, have the potential to decrease side effects and complications and to simplify the care of those ventilatory failure patient who still have a trace of spontaneous ventilatory capacity.

The present study was designed to address the following questions: ( $a$ ) To what extent can ITI improve the efficiency of ventilation when applied to animals with normal lungs who have ventilatory insufficiency? $(b)$ How much of this improvement is caused by dead space reduction (VD) and how much is caused by nonconvective mechanisms of transport? $(c)$ What is the optimal combination of flow rate and ITI catheter position? (d) What are the hemodynamic effects of ITI?

\section{Methods}

The materials and methods used in this study are described under the following subsections: $(a)$ animal preparation and instrumentation; (b) data acquisition of measured parameters and the calibration procedures; $(c)$ calculation of secondary parameters and data analysis; and $(d)$ outline of experimental design and protocol.

\section{Animal preparation and instrumentation}

Seven mongrel dogs of either gender, 19.5-34 kg body wt (mean \pm SD $27.2 \pm 4.2 \mathrm{~kg}$ ) were anesthetized with $30 \mathrm{mg} / \mathrm{kg}$ i.v. sodium pentobarbital. An intravenous infusion of lactated Ringer's solution was started at $1 \mathrm{ml} / \mathrm{kg}$ per $\mathrm{h}$ and an endotracheal tube (ETT) $(9.5 \mathrm{~mm}$ i.d.) was inserted so that the free end of the ETT lined up with the dog's canine incisors. The ETT cuff was inflated and the tube was secured with tape. The dogs were placed in the left lateral decubitus position. An arterial line was inserted into the left radial artery via a cutdown and connected to a pressure transducer (Baxter solid state model \#90603A-16-18; Space Labs, Inc., Redmond, WA). Electrocardiogram (ECG) needle electrodes were connected and a urinary catheter was inserted in the male dogs. A flow-directed balloon catheter (Swan-Ganz catheter model 93A-140-7F; American Edwards Laboratories, Santa Ana, CA) was inserted into the right external jugular vein via a cutdown and advanced so that pulmonary artery pressure was measured and a pulmonary wedge pressure was obtained within two heart beats from the balloon inflation. The Swan-Ganz catheter thermistor was also used to monitor core temperature.

An esophageal balloon was inserted so that its tip was $5 \mathrm{~cm}$ mouthward from the dog's palpable point of maximal cardiac impulse. The balloon was inflated with $1.2 \pm 0.2 \mathrm{ml}$ of air and the catheter was connected to a pressure transducer (model MP- $45 \pm 18 \mathrm{~cm} \mathrm{H}_{2} \mathrm{O}$; Validyne Engineering Corp., Northridge, CA). The distance from the free end of the ETT to the main carina was then measured using a fiberoptic bronchoscope. Fig. 1 shows the instrumentation of the airways. The ITI catheter length (polyethylene tubing $2 \mathrm{~mm}$ o.d., $1.6 \mathrm{~mm}$ i.d.) was adjusted so that its tip was in the trachea, $0.5 \mathrm{~cm}$ mouthward from the main carina. A pneumotachograph (Fleish model 2; Gould, Inc., Cardio Pulmonary Instruments, Houston, TX), coupled to a differential pressure transducer (model MP- $45 \pm 2 \mathrm{~cm} \mathrm{H}_{2} \mathrm{O}$; Validyne) was connected in line. An inductive plethysmograph (model 10.9000; Respitrace Corp., Ardsley, NY) was placed around the chest wall and abdomen with appropriately sized belts. A " $T$ " connector allowed constant flow of $\mathrm{O}_{2}$ air mixture $\left(40 \pm 1 \% \mathrm{O}_{2}\right)$ at 15 liters/min with an added rebreathing section of $140 \mathrm{ml}$. The $\mathrm{FI}_{\mathrm{O}_{2}}$ was constantly monitored with an oxygen monitor (model 5590; Hudson, Ventronics Div., location not available). The same gas mixture was also used for the insufflation (see below). $\mathrm{A} \mathrm{CO}_{2}$ analyzer (model CD-102-41-01; Puritan-Bennett/ Datex, Helsinki, Finland) and a nitrogen analyzer (Nitralyzer 505; Med Science, St. Louis, MO) were connected via needles inserted through the ETT wall $1.5 \mathrm{~cm}$ from the connector.

\section{Data acquisition of measured parameters}

Each set of data (see Experimental design section below) consisted of measurements and recording of the following parameters: $\mathrm{O}_{2}$ and $\mathrm{CO}_{2}$

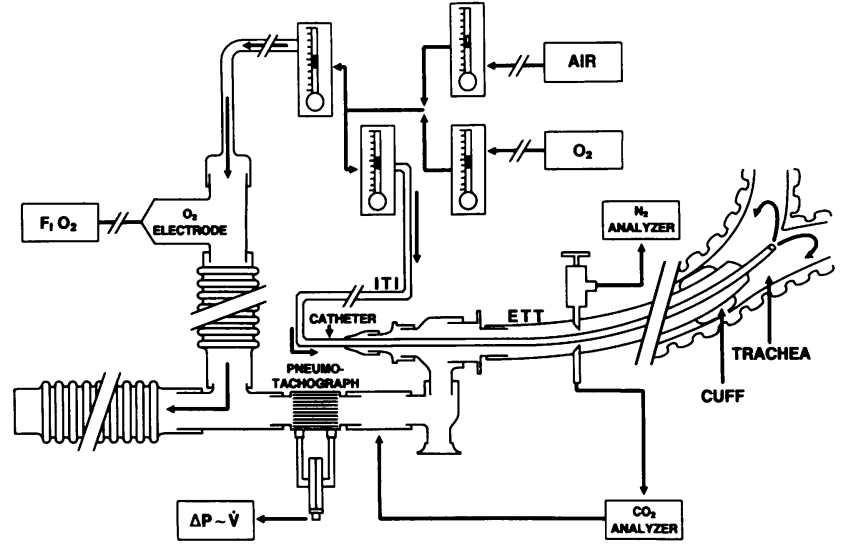

Figure 1. Schematic drawing of the instrumentation of the dog's airways. The intratracheal insufflation (ITI) catheter was inserted through the endotracheal tube (ETT) and was positioned with its tip $0.5 \mathrm{~cm}$ mouthward from the tracheal carina (by curved arrows at tip of catheter). A pneumotachograph measured the flow ( $\dot{\mathrm{V}}) . \mathrm{CO}_{2}$ and $\mathrm{N}_{2}$ analyzers were used to measure these gases levels. $\mathrm{An}_{2}$ monitor was used to follow the inspiratory fraction of oxygen $\left(\mathrm{FI}_{\mathrm{O}_{2}}\right)$.

tensions, $\mathrm{pH}, \mathrm{O}_{2}$ saturation and hemoglobin concentration in arterial and mixed venous blood samples were measured by blood gas analyzers (model ABL4; Radiometer, Copenhagen, Denmark). Samples were analyzed within $5 \mathrm{~min}$ of blood withdrawal. Core body temperature and $\mathrm{FI}_{\mathrm{O}_{2}}$ were recorded, and pulmonary wedge and central venous pressures were measured through the distal and proximal ports of the Swan-Ganz catheter, respectively. Cardiac output was measured with a cardiac output computer ( model 9520A; American Edwards Laboratories) by the thermodilution technique using three $10-\mathrm{ml}$ injectates of $0.9 \% \mathrm{NaCl}$ solution at room temperature per measurement. In addition, a 60 -s continuous segment of seven parameters was digitized at 50 samples/s ( 12 bit A/D, $\pm 5 \mathrm{~V}$ ); and stored in digital form for further analysis (A/D converter model ADA1 100; Real Time Devices, State College, PA and AST computer, 286 processor; Atlantis Data Acquisition Software, Lakeshore Technologies, Chicago, IL). The recorded parameters were $(a)$ arterial blood pressure; $(b)$ ECG; $(c)$ flow rate from the pneumotachograph; $(d)$ volume as sum of abdomen and chest wall signals from the inductive plethysmograph; $(e)$ esophageal pressure; $(f)$ pulmonary artery pressure; and $(g)$ airway opening $\mathrm{CO}_{2}$ concentration. The $\mathrm{CO}_{2}$ analyzer with the catheter used for sample withdrawal has a 1.6-s delay that was compensated for during the digital data processing (see below). The total time needed for a complete set of data acquisition (manual and computerized) was $9 \pm 2 \mathrm{~min}$.

Calibration procedures were as follows: Arterial and pulmonary blood pressure transducers were calibrated against a mercury manometer. The esophageal pressure transducer was calibrated with a water manometer. Flow rate was calibrated with a water-sealed spirometer (model 06001; Warren E. Collins Inc., Braintree, MA). The same spirometer was also used to calibrate the Respitrace. The blood gas analyzer runs a self-calibration procedure against standard gas and solutions every $2 \mathrm{~h}$ and was used to calibrate the $\mathrm{CO}_{2}$ analyzer. The oxygen monitor was calibrated with room air and $100 \% \mathrm{O}_{2}$.

\section{Calculation of secondary parameters and data analysis}

Data analysis was done using a computer algorithm written in FORTRAN 77. Program inputs were the 60-s segments of sampled data and the values of the individually recorded parameters entered manually via the keyboard. The secondary parameters are subdivided into three groups: $(a)$ respiratory mechanics parameters; $(b)$ gas exchange parameters; and $(c)$ hemodynamic parameters. The ventilatory efficiency index that combines the respiratory mechanics and gas exchange information into a single parameter is presented separately.

Respiratory mechanics parameters. Data from the pneumotacho- 
graph, esophageal balloon, and Respitrace were used to calculate the following parameters: spontaneous tidal volume $\left(V_{T}\right)$ was calculated for each breath by integrating the flow $(\dot{V})$ after subtraction of the ITI flow $\left(\dot{\mathrm{V}}_{\mathrm{ITI}}\right)$, calculated as the time-averaged flow

$V_{\mathrm{T}}=\int_{\mathrm{t}_{0}}^{\mathrm{t}_{0}+\tau_{\mathrm{I}}}\left(\dot{V}-\dot{V}_{\mathrm{ITI}}\right) d t$

where $T_{I}$ is the duration of inspiration. A mean $V_{T}$ was calculated from all the breaths in each 60 -s segment. Values of $V_{T}$ calculated from the flow signal correlated well with those measured with the Respitrace. The respiratory rate (f) is the number of breaths identified in the 60-s sample. Spontaneous breathing minute ventilation $\left(\dot{V}_{E}\right)$ was calculated by summing the $V_{T}$ values during the $60 \mathrm{~s}$. The integral of esophageal pressure $P_{e s}$ (relative to baseline) multiplied by the corresponding volume increment was calculated during each inspiration to give the inspiratory external work of breathing (WI) per breath

$W I=\int_{V\left(t_{0}\right)}^{V\left(t_{0}+T_{1}\right)}\left(P_{e s}-P_{e s b_{\text {baseline }}}\right) d v$.

The 60-s sum of the individual breath's WI values was calculated as the spontaneous inspiratory work of breathing per minute (WI/min).

Gas exchange parameters. The secondary gas exchange parameters were calculated from the arterial and venous blood gases, the $\mathrm{O}_{2}$ monitor $\left(\mathrm{FI}_{\mathrm{O}_{2}}\right)$, the airway opening (ao) $\mathrm{CO}_{2}$ analyzer output $\mathrm{FaO}_{\mathrm{CO}_{2}}$, the flow ( $\mathrm{VaO}$ ) and the cardiac output (Q). The rate of $\mathrm{CO}_{2}$ elimination $\left(\dot{\mathrm{V}} \mathrm{CO}_{2}\right)$ was calculated as the time averaged product of $\dot{\mathrm{V}} \mathrm{aO}$ and $\mathrm{FaO}_{\mathrm{CO}_{2}}$ after adjusting for the time delay of the $\mathrm{CO}_{2}$ analyzer. Oxygen consumption $\left(\mathrm{V}_{2}\right)$ was calculated from the inverted Fick cardiac output equation as $\dot{\mathrm{V}}_{2}=\mathrm{Q}\left(\mathrm{Ca}_{\mathrm{O}_{2}}-\mathrm{Cv}_{\mathrm{O}_{2}}\right)$ where $\mathrm{Ca}_{\mathrm{O}_{2}}$ and $\mathrm{Cv}_{\mathrm{O}_{2}}$ are the arterial and mixed venous $\mathrm{O}_{2}$ contents, respectively (see below). The respiratory quotient (RQ) was calculated from the ratio $\dot{\mathrm{V}} \mathrm{CO}_{2} / \dot{\mathrm{VO}}_{2}$. Alveolar ventilation $\left(\dot{\mathrm{V}}_{\mathrm{A}}\right)$ was calculated as $\dot{\mathrm{V}}_{\mathrm{A}}=\dot{\mathrm{V}}_{\mathrm{CO}_{2}} / \mathrm{FA}_{\mathrm{CO}_{2}}$, while $\mathrm{FACO}_{2}$ was estimated from the arterial $\mathrm{PCO}_{2}\left(\mathrm{~Pa}_{\mathrm{CO}_{2}}\right)$, the barometric pressure $\left(\mathrm{P}_{\mathrm{B}}\right)$ and water vapor pressure $\mathrm{PH}_{2} \mathrm{O}$; $\left[\mathrm{FA}_{\mathrm{CO}_{2}}=\mathrm{Pa}_{\mathrm{CO}_{2}} /\left(\mathrm{P}_{\mathrm{B}}\right.\right.$ - $\left.\mathrm{PH}_{2} \mathrm{O}\right)$ ]. The Bohr dead space $\left(\mathrm{V}_{\mathrm{D}} \mathrm{Bohr}\right)$ was calculated as the difference between minute ventilation and alveolar ventilation per breath: $\mathrm{V}_{\mathrm{D}}$ Bohr $=\left(\dot{\mathrm{V}}_{\mathrm{E}}-\dot{\mathrm{V}}_{\mathrm{A}}\right) / \mathrm{f}$.

Arterial and mixed venous $\mathrm{O}_{2}$ saturations were calculated by the Hill equation (14) with canine $\mathrm{P}_{50}$ corrected for $\mathrm{pH}$. Arterial and venous $\mathrm{O}_{2}$ contents were calculated from the corresponding saturation and partial pressures and the measured hemoglobin concentration. Pulmonary capillary $\mathrm{O}_{2}$ content was similarly calculated using an estimate of alveolar gas $\mathrm{PO}_{2}\left(\mathrm{PA}_{\mathrm{O}_{2}}\right)$ as the pulmonary capillary $\mathrm{PO}_{2}\left(\mathrm{PPC}_{\mathrm{O}_{2}} ; \mathrm{PA}_{\mathrm{O}_{2}}\right.$ $=\mathrm{P}_{\mathrm{O}_{2}}-\mathrm{Pa}_{\mathrm{CO}_{2}} / \mathrm{RQ}$; where $\mathrm{PI}_{\mathrm{O}_{2}}$ is the inspiratory $\mathrm{O}_{2}$ partial pressure calculated as $\mathrm{PI}_{\mathrm{O}_{2}}=\mathrm{FI}_{\mathrm{O}_{2}}\left(\mathrm{~PB}-\mathrm{PH}_{2} \mathrm{O}\right)$. This $\mathrm{PA}_{\mathrm{O}_{2}}$ value was also used to calculate the alveolar-arterial difference of $\mathrm{O}_{2} ;\left[(\mathrm{A}-\mathrm{a}) \mathrm{DO}_{2}\right]$. The $\mathrm{O}_{2}$ contents in arterial, venous, and pulmonary capillary blood were used to estimate the shunt fraction using: $\mathrm{Qs} / \mathrm{Qt}=\left(\mathrm{CpcO}_{2}-\mathrm{CaO}_{2}\right) /\left(\mathrm{CpcO}_{2}\right.$ $\left.-\mathrm{CvO}_{2}\right)$.

Hemodynamic parameters. The hemodynamic parameters were calculated from the blood pressures measured via the arterial line and the Swan-Ganz catheter, through analysis of the ECG signal, and by using the thermodilution cardiac output technique. The following parameters were calculated from the data: systolic, diastolic, as well as mean and pulse systemic and pulmonary artery pressures. The heart rate was calculated from the autocorrelation function of the ECG signal, and the cardiac output was estimated as the arithmetic mean of the triplicate readings. Systemic vascular resistance (SVR) was calculated as $\mathrm{SVR}=(\mathrm{MAP}-\mathrm{CVP}) / \mathrm{Q}$, where MAP is the mean arterial pressure and CVP is the central venous pressure. Pulmonary vascular resistance (PVR) was similarly calculated as $P V R=\left(M P P-P_{\text {wedee }}\right) / Q$, where MPP is the mean pulmonary pressure and $P_{\text {wedee }}$ is the pulmonary wedge pressure.

Ventilatory efficiency index. To assess the effect of ITI on the dog's ventilatory efficiency, the experimental data were analyzed using a ventilatory efficiency index (VEI). We define $\mathrm{VEI}=\dot{\mathrm{VCO}}_{2} /\left(\mathrm{Pa}_{\mathrm{CO}_{2}}\right.$ $\times \mathrm{WI} / \mathrm{min}$ ). VEI combines the effects of three independent parameters: rate of $\mathrm{CO}_{2}$ elimination, which is the ultimate product of gas exchange; $\mathrm{Pa}_{\mathrm{CO}_{2}}$, an index of the total body $\mathrm{CO}_{2}$ stores and also a "driving force" for $\mathrm{CO}_{2}$ transport; and the mechanical work (WI/min) needed to mobilize $\mathrm{CO}_{2}$. A normal subject, who breathes 15 breaths $/ \mathrm{min}$ with $\mathrm{V}_{\mathrm{T}}=0.6$ liter, develops $-5 \mathrm{~cm} \mathrm{H}_{2} \mathrm{O}$ esophageal pressure change with each breath, eliminates $\mathrm{CO}_{2}$ at a rate $\dot{\mathrm{VCO}}_{2}=200 \mathrm{ml} / \mathrm{min}$, and has $\mathrm{Pa}_{\mathrm{CO}_{2}}=40 \mathrm{mmHg}$; VEI is found to be $0.22(\mathrm{ml} / \mathrm{min}) /\left(\mathrm{cm} \mathrm{H}_{2} \mathrm{O}\right.$ $\mathrm{mmHg}$-liter/min ). Note that both $\mathrm{VCO}_{2}$ and $\mathrm{WI} / \mathrm{min}$ are proportional to the body size, which tend to cancel out in the expression for VEI, while $\mathrm{Pa}_{\mathrm{CO}_{2}}$ and $\mathrm{P}_{\mathrm{es}}$ are relatively independent of body size. As a result, VEI is a parameter that is relatively independent of body size.

\section{Experimental design and protocol}

Initial control data were taken $30 \mathrm{~min}$ after the completion of the animal instrumentation. Intravenous infusion of pentobarbital at $3 \pm 0.6$ $\mathrm{mg} / \mathrm{kg}$ per $\mathrm{h}$ and pavulon at $35 \pm 5 \mu \mathrm{g} / \mathrm{kg}$ per $\mathrm{h}$ were then started. The pentobarbital rate was $\sim 10 \%$ of the initial induction dose infused per hour. The pavulon rate corresponds to rates shown to achieve $80 \%$ reduction in twitch response in dogs (15), and to cause significant reduction in diaphragmatic muscle activity (16). At least 40 min were allowed for stabilization after the onset of infusion. At the end of this period, a control data set was taken. ITI was then started at 0.05 liter/ min per $\mathrm{kg}$ with the ITI catheter placed at the main carina. After 30 min, a data set was taken and ITI was turned off. A 30-min period of control was again followed by ITI at a flow of $0.10 \mathrm{liter} / \mathrm{min}$ per $\mathrm{kg}$. Similar control-ITI periods were repeated with ITI of 0.15 and 0.2 liter/min per $\mathrm{kg}$, all with the tip of the ITI catheter positioned at the main carina. The next ITI run was done after the catheter was advanced $4 \mathrm{~cm}$ beyond the main carina into one of the main bronchi $(\mathrm{Br})$. The ITI flow was set to $0.15 \mathrm{liter} / \mathrm{min}$ per $\mathrm{kg}$ and a control followed by an ITI cycle was started. The ITI catheter was then with-

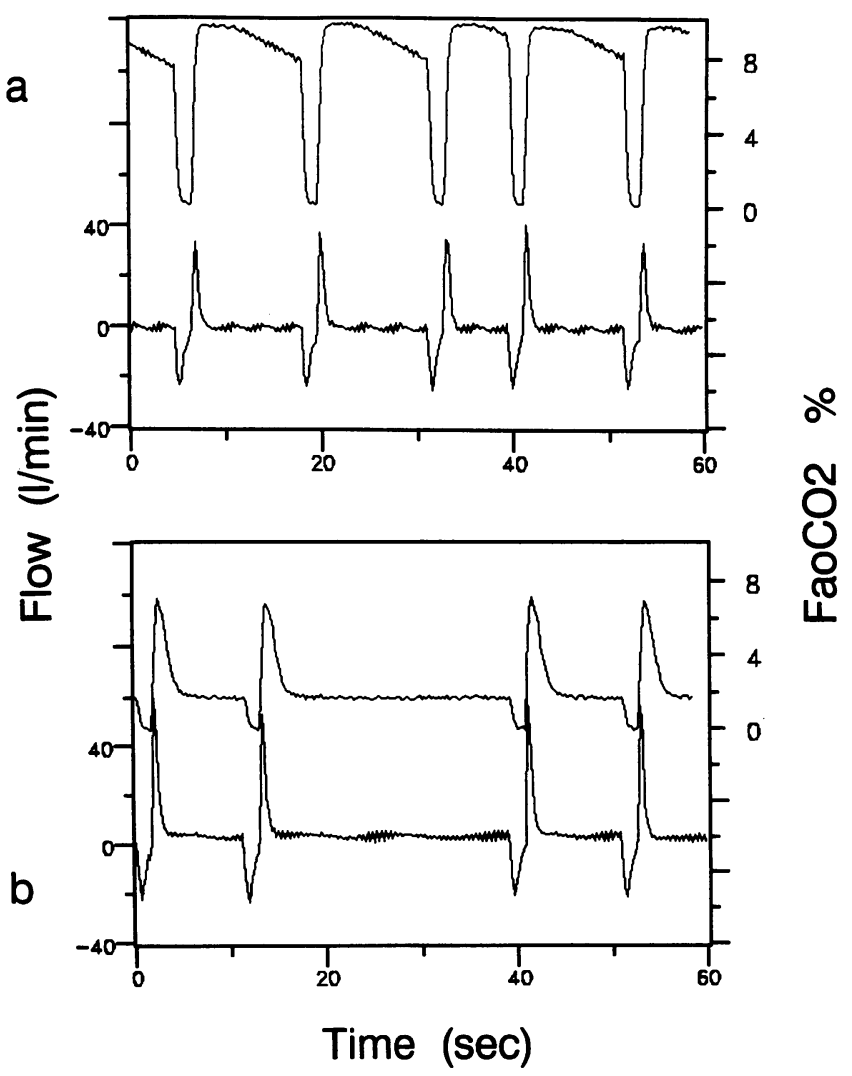

Figure 2. Airway opening flow rate and $\mathrm{CO}_{2}$ fraction $\left(\mathrm{FaO}_{\mathrm{CO}_{2}}\right)$ during control $(a)$ and during intratracheal insufflation at $0.15 \mathrm{liter} / \mathrm{min}$ per $\mathrm{kg}(b)$. Note the nonzero flow and $\sim 2 \% \mathrm{FaO}_{\mathrm{CO}_{2}}$ in $b$. 


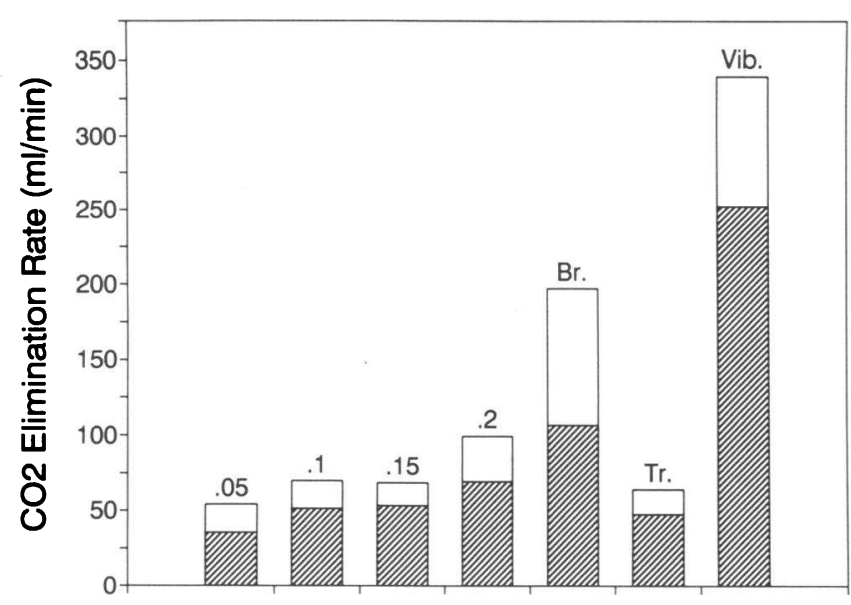

\section{ITI Status}

Figure 3. Rate of $\mathrm{CO}_{2}$ elimination by intratracheal insufflation (ITI) between breaths. All the control values (i.e., no ITI) were zero. Rates were significantly higher with flows greater than 0.05 liter $/ \mathrm{min}$ per $\mathrm{kg}$ with the catheter in the carina; were higher with the catheter in a mainstem bronchus $(B r$.$) vs. the trachea (T r$.$) ; and with vibration$ (Vib.) vs. no vibration. Flow rates were as indicated above bars and 0.15 liter $/ \mathrm{min}$ per $\mathrm{kg}$ at $\mathrm{Br}$., $\mathrm{Tr}$., and with vibration. mean values; $\square, 1$ SD from the mean.

drawn $8 \mathrm{~cm}$ for the next run so that its tip was in the trachea ( $T \mathrm{r}$.), $4 \mathrm{~cm}$ from the carina. ITI flow at $\mathrm{Tr}$. was also set to $0.15 \mathrm{liter} / \mathrm{min}$ per $\mathrm{kg}$.

For the last set of runs, the catheter was readvanced to the main carina with a flow of $0.15 \mathrm{liter} / \mathrm{min}$ per $\mathrm{kg}$. After a control period as in the other runs, high frequency $(22 \mathrm{~Hz})$, low amplitude $(0.2 \mathrm{~cm})$ vibration of the inferior chest wall was started. An electric motor was used to drive a flat, round hard rubber disc, $12 \mathrm{~cm}$ in diameter, up and down in a corresponding indentation made in the surface of the experimental table $(60 \times 120 \mathrm{~cm})$. The mean position of the vibrating disc was elevated $0.4 \mathrm{~cm}$ above the surface of the table. The disc was directly under the dog's left scapula. A 5- $\mathrm{cm}_{2} \mathrm{O}$ continuous positive airway pressure valve was used on the airway outlet in these control and vibration periods.

\section{Results}

The constant infusion of pentobarbital and pavulon reduced alveolar ventilation in all the dogs. The mean $\mathrm{Pa}_{\mathrm{CO}_{2}}$, calculated from the data taken during all the control periods $(n=7 \times 7$ $=49$ ), was $62.9 \pm 17.8 \mathrm{mmHg}($ mean $\pm \mathrm{SD})$, which is $57 \%$ greater than normal canine $\mathrm{Pa}_{\mathrm{CO}_{2}}$ (14). Overall control minute ventilation $\left(\dot{\mathrm{V}}_{\mathrm{E}}\right)$ was $2.8 \pm 1.7$ liter $/ \mathrm{min}(0.104 \pm 0.067$ liter/ min per $\mathrm{kg})$, with $\mathrm{V}_{\mathrm{T}}$ of $434 \pm 151 \mathrm{ml}(15.9 \pm 4.3 \mathrm{ml} / \mathrm{kg})$. The control $\mathrm{CO}_{2}$ elimination rate $\left(\dot{\mathrm{V}}_{2} \mathrm{CO}_{2}\right)$ was $123 \pm 47 \mathrm{ml} / \mathrm{min}$ $(4.50 \pm 1.59 \mathrm{ml} / \mathrm{min}$ per $\mathrm{kg})$, with oxygen consumption rate $\left(\dot{\mathrm{V}}_{2}\right)$ of $148 \pm 29 \mathrm{ml} / \mathrm{min}(5.48 \pm 0.58 \mathrm{ml} / \mathrm{min}$ per $\mathrm{kg})$. The alveolar ventilation rate $\left(\dot{\mathrm{V}}_{\mathrm{A}}\right)$ during the control periods was $1.56 \pm 0.92 \mathrm{liter} / \mathrm{min}(0.057 \pm 0.034 \mathrm{liter} / \mathrm{min}$ per $\mathrm{kg})$ and the Bohr dead space, consisting of the dog's airways, as well as the tubing and pneumotachograph, was $0.166 \pm 0.077$ liter $(6.24 \pm 2.87 \mathrm{ml} / \mathrm{kg})$. Despite the reduced alveolar ventilation, alveolar, arterial, and mixed venous oxygenation were kept normal or above normal $\left(\mathrm{PA}_{\mathrm{O}_{2}}=197 \pm 45\right.$ Torr, $\mathrm{Pa}_{\mathrm{O}_{2}}=137 \pm 27$ Torr, and $\mathrm{Pv}_{\mathrm{O}_{2}}=59 \pm 9$ Torr) by maintaining $\mathrm{F}_{\mathrm{I}} \mathrm{O}_{2}$ at $0.40 \pm 0.01$. The shunt and $(\mathrm{A}-\mathrm{a}) \mathrm{Do}_{2}$ during the control periods were above normal $(15.8 \pm 8.6 \%$ and $60.0 \pm 26.2 \mathrm{mmHg}$, respectively), probably reflecting the contribution of hypoventilated regions of the lung to the inhomogeneity of the ventilation-perfusion distribution. Control mean arterial pressure, cardiac output and heart rate were above normal $(123 \pm 10$ $\mathrm{mmHg}, 4.03 \pm 0.86$ liters $/ \mathrm{min}(150 \pm 34 \mathrm{ml} / \mathrm{min}$ per $\mathrm{kg})$, and
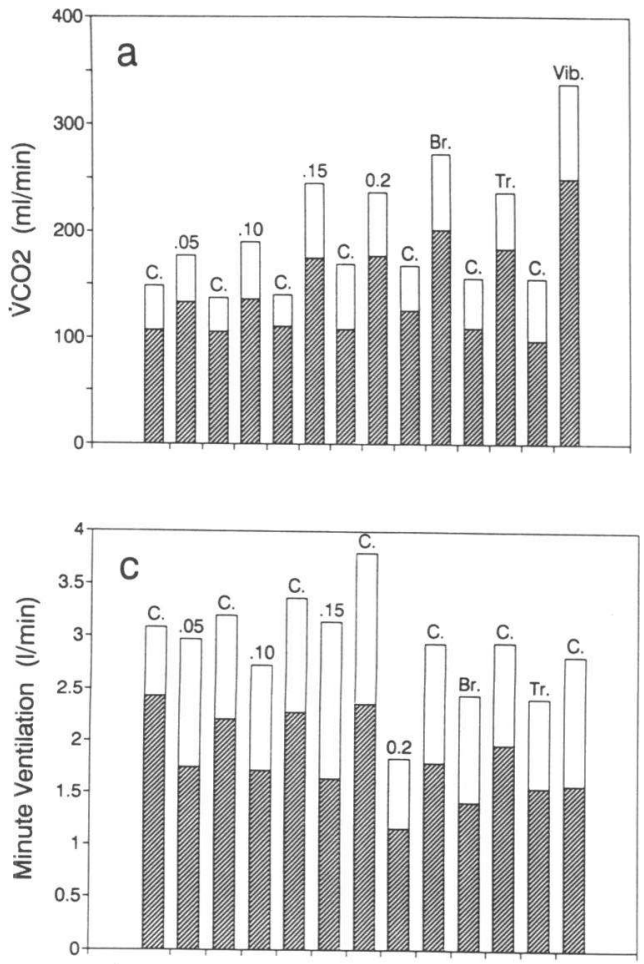

ITI Status
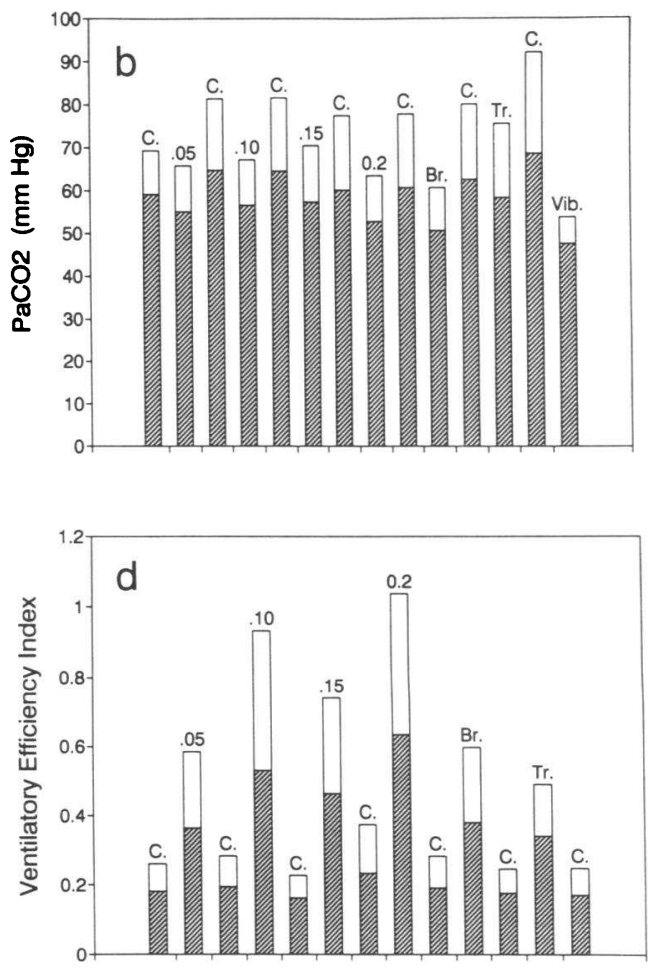

ITI Status
Figure 4. Effect of ITI on $(a)$ $\mathrm{CO}_{2}$ elimination rate $\left(\mathrm{V}_{\mathrm{CO}_{2}}\right)$; (b) $\mathrm{Pa}_{\mathrm{CO}_{2}} ;(c)$ minute ventilation; and $(d)$ on the ventilatory efficiency index. $C$, control; 0.05, 0.1, 0.15, and 0.2 indicate ITI flow rates in liter $/ \mathrm{min}$ per $\mathrm{kg}$. $\mathrm{Br}$. and $\mathrm{Tr}$. indicate catheter tip position in a mainstem bronchus and in the trachea, respectively. $\mathrm{Vib}$ in $(a)$ and $(b)$ indicate the values during vibration. In the absence of breaths, the corresponding values could not be calculated for $(c)$ and (d). Flow rates were as indicated above bars and 0.15 liter/min per $\mathrm{kg}$ at $\mathrm{Br}$., $\mathrm{Tr}$., and with vibration. $\square$, mean values, $\square, 1$ SD from the mean. 
$120 \pm 33$ beats/min, respectively). This is probably attriuuted to a direct hemodynamic stimulating effect of both pentobarbital and pavulon (17-18). Control mean pulmonary artery pressure and resistance were $19.2 \pm 3.7 \mathrm{mmHg}$ and $217 \pm 100$ dyn $\cdot \mathrm{s} \cdot \mathrm{cm}^{-5}$, respectively. Control systemic vascular resistance was $2.9 \pm 1.2 \times 10^{3} \mathrm{dyn} \cdot \mathrm{s} \cdot \mathrm{cm}^{-5}$. Thus, pentobarbital and pavulon at the specified dose caused significant hypoventilation with normal blood and tissue oxygenation and caused hemodynamic stimulation. This animal model was stable throughout the experiment with no significant temporal trends of the parameters.

The most significant effect of ITI was the appearance of $\mathrm{CO}_{2}$ removal from the animals in the periods between breaths. Fig. 2 shows airway-opening flow and $\mathrm{CO}_{2}$ concentration during a control run (Fig. $2 a$, no ITI), and during ITI at $0.151 / \mathrm{kg}$ per min (Fig. $2 b$ ). In Fig. $2 a$, there was no ITI, so that the flow between breaths was zero and so was the $\mathrm{CO}_{2}$ elimination. In Fig. $2 b$, ITI flow was present so that $\mathrm{CO}_{2}$ was removed at a rate equal to the product of the flow rate and the $\mathrm{CO}_{2}$ concentration. Fig. 3 shows the time-averaged $\mathrm{CO}_{2}$ elimination rate during the periods between breaths for the seven ITI conditions. With ITI delivered to the main carina (CAR position) at $0.05-$ 0.2 liter $/ \mathrm{min}$ per $\mathrm{kg}$, time-averaged $\mathrm{CO}_{2}$ elimination between breaths was $48 \pm 16 \mathrm{ml} / \mathrm{min}$ with a small advantage of ITI $>0.05(P<0.05)$ and no significant differences between the ITI flows of $0.1,0.15$, and $0.2 \mathrm{liter} / \mathrm{min}$ per $\mathrm{kg}$. When the ITI catheter was advanced $4 \mathrm{~cm}$ from the main carina into the mainstem bronchus ( $\mathrm{Br}$. position), $\mathrm{CO}_{2}$ elimination between breaths increased to $77 \pm 48 \mathrm{ml} / \mathrm{min}$. Pulling the catheter out 4 $\mathrm{cm}$ into the trachea ( $\mathrm{Tr}$. position) reduced $\mathrm{CO}_{2}$ removal to $34 \pm 13 \mathrm{ml} / \mathrm{min}(P<0.05$, paired Student's $t$ test $)$. These values represent 39,63 , and $28 \%$ of the control $\mathrm{VCO}_{2}$ for $\mathrm{CAR}, \mathrm{Br}$., and Tr. positions, respectively.

ITI at $0.15-0.2 \mathrm{liter} / \mathrm{min}$ per $\mathrm{kg}$ increased overall $\mathrm{V}_{\mathrm{CO}_{2}}$ (i.e., between breaths and during breaths combined) by $>50 \%$ over control $(P<0.05$, paired Student's $t$ test; Fig. $4 a)$. There was a $10 \%$ decrease of $\mathrm{Pa}_{\mathrm{CO}_{2}}$ at these flow rates $(P<0.05$; Fig. 4 $b)$, despite a $28 \%$ fall of $\dot{\mathrm{V}}_{\mathrm{E}}(P<0.05$; Fig. $4 c)$, and a $32 \%$ decrease of the work of breathing $(P<0.05)$. The substantial contribution of ITI is demonstrated by calculating the index of ventilatory efficiency (VEI, see Methods). VEI increased $2.80 \pm 1.77$-fold among all the ITI flow rates and positions, with statistical significance relative to control in all cases except ITI $=0.05 \mathrm{liter} / \mathrm{min}$ per $\mathrm{kg}(\mathrm{Fig} .4 d)$. This increase in VEI reflects the combined effects of higher $\mathrm{VCO}_{2}$, with lower $\mathrm{PA}_{\mathrm{CO}_{2}}$, even though $\dot{\mathrm{V}}_{\mathrm{E}}$ and $\mathrm{WI} / \mathrm{min}$ were diminished. The effects of ITI on alveolar ventilation and on the Bohr dead space are shown in Fig. 5. Note that the physiological meaning of negative Bohr dead space is that $\dot{\mathrm{V}}_{\mathrm{A}}$ is larger than spontaneous breathing $\dot{\mathrm{V}}_{\mathrm{E}}$.

The effects of ITI on oxygen transport are listed in Table I. In general, except when vibration was used (see below), ITI did not change the oxygen consumption or transport in the lungs and through the tissues, nor did it affect the shunt or the (Aa) $\mathrm{DO}_{2}$. The hemodynamic effects of ITI are listed in Table II. There were no differences in these parameters between the control periods and the ITI periods when vibration was not used.

The effect of ITI flow rate. ITI at flows above $0.05 \mathrm{liter} / \mathrm{min}$ per kg eliminated $10 \%$ more $\mathrm{CO}_{2}$ than at 0.05 liter $/ \mathrm{min}$ per $\mathrm{kg}$ $(P<0.05)$, but there were no statistically significant differences of $\dot{\mathrm{VCO}}_{2}$ among the ITI flows in the range 0.1-0.2 liter/ min per kg. A similar pattern was found when the differences in VEI were examined, where VEI was significantly different from control in all flow rates except with $0.05 \mathrm{liter} / \mathrm{min}$ per $\mathrm{kg}$.
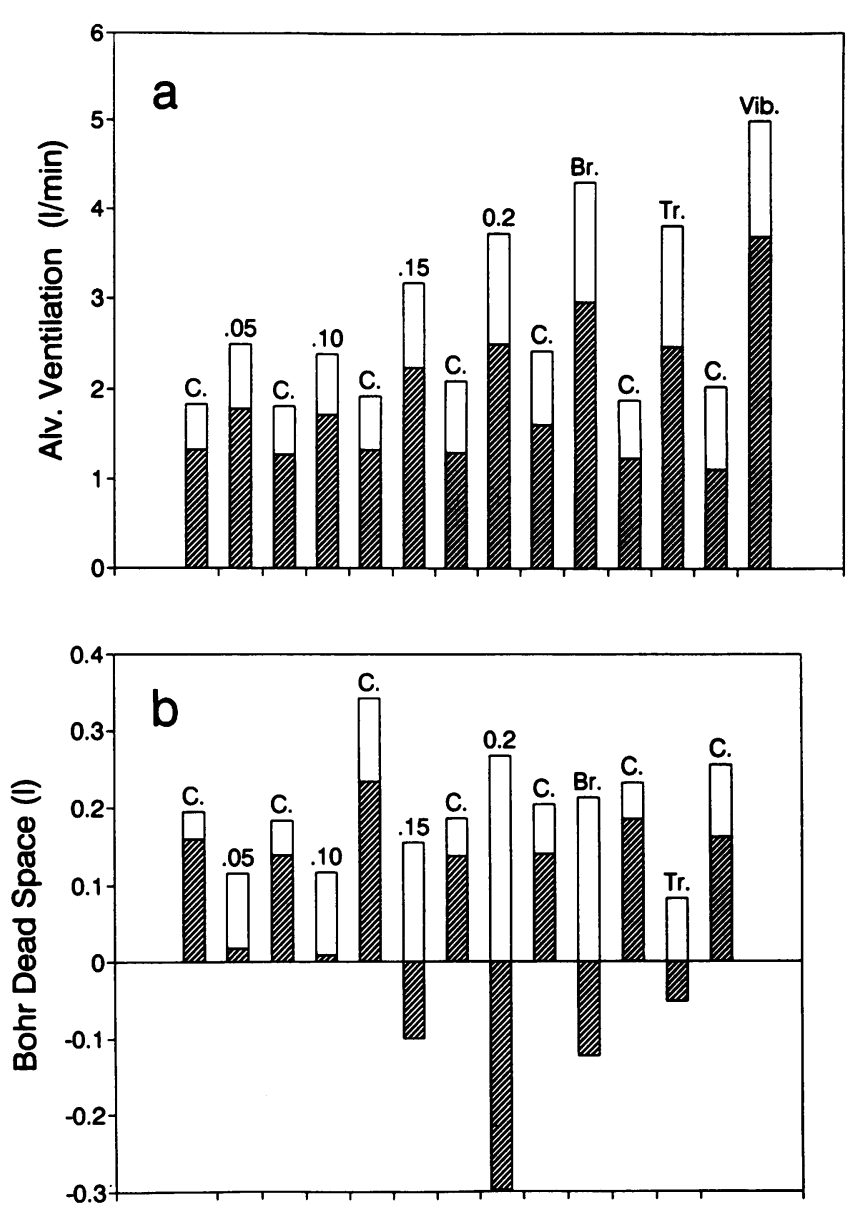

\section{ITI Status}

Figure 5. Alveolar ventilation ( $a$ ) and Bohr dead space (b) during control $(C$.) and ITI. See legend to Fig. 3 for details of bar titles. Note the substantial increase of alveolar ventilation during ITI and the reduced or negative Bohr dead space. Negative values reflect conditions in which alveolar ventilation is greater than the spontaneous breathing minute ventilation.

The individual parameters from which VEI was calculated (i.e., $\mathrm{V}_{\mathrm{CO}_{2}}, \mathrm{~Pa}_{\mathrm{CO}_{2}}$, and $\mathrm{WI}$ ) were significantly different from control with the 0.2 liter $/ \mathrm{min}$ per $\mathrm{kg}$ flow rate. $\mathrm{Pa}_{\mathrm{CO}_{2}}$ was also significantly different from control $(P=0.0015)$ with flow of $0.15 \mathrm{liter} / \mathrm{min}$ per $\mathrm{kg}$ and WI was significantly different from control with $0.1 \mathrm{liter} / \mathrm{min}$ per $\mathrm{kg}(P=0.011)$. Thus, ITI effectively increased gas exchange and ventilatory efficiency with flows as low as $0.1 \mathrm{liter} / \mathrm{min}$ per $\mathrm{kg}$. No effect was found on oxygenation and hemodynamic parameters.

The effects of ITI catheter position. The ITI catheter was placed with its tip at the main carina, $4 \mathrm{~cm}$ into a mainstem bronchus (Br.), and $4 \mathrm{~cm}$ from the carina in the trachea (Tr.). The flow in all three locations was $0.15 \mathrm{liter} / \mathrm{min}$ per $\mathrm{kg} . \mathrm{CO}_{2}$ removal between breaths was better with the catheter at CAR than at $\operatorname{Tr}$. $(47.7 \pm 15.5$ vs. $34.3 \pm 13.3 \mathrm{ml} / \mathrm{min}$, respectively; $P$ $=0.0523)$; and better with the catheter tip at $\mathrm{Br}$. than at $\mathrm{Tr}$. ( $76.7 \pm 47.9$ vs. $34.3 \pm 13.3 \mathrm{ml} / \mathrm{min}$, respectively; $P=0.0413$ ). The difference between $\mathrm{Br}$. and CAR had a chance probability of $P=0.0794$. VEI was higher in $\mathrm{Br}$. than in CAR and in Tr. $(3.92 \pm 2.83$ vs. $2.95 \pm 1.52$ and $1.91 \pm 0.19$, respectively). Only the differences relative to $\operatorname{Tr}$. were statistically significant. Thus, ITI delivered at or distal to the main carina is substan- 
Table I. Oxygen Consumption $\left(\dot{V}_{2}\right)$, Mixed Venous Oxygen Saturation $S V_{O_{2}}$, Shunt $(Q s / Q t)$, and Alveolar-arterial Difference of $\mathrm{O}_{2}(A-a) \mathrm{DO}_{2}$ during Control Periods (Cont), ITI, and ITI with Vibration (ITI + VIB)

\begin{tabular}{|c|c|c|c|c|c|c|c|c|}
\hline & \multicolumn{8}{|c|}{ With catheter tip at the main carina } \\
\hline & Cont & ITI & Cont & ITI & Cont & ITI & Cont & ITI \\
\hline$\dot{\mathrm{V}}_{\text {ITI }}($ liter/min per kg) & \multicolumn{2}{|c|}{0.05} & \multicolumn{2}{|c|}{0.1} & \multicolumn{2}{|c|}{0.15} & \multicolumn{2}{|c|}{0.2} \\
\hline$\dot{\mathrm{V}}_{2}(\mathrm{ml} / \mathrm{min})$ & 125 & 131 & 142 & 137 & 144 & 147 & 149 & 147 \\
\hline $\mathrm{SD}$ & 24 & 17 & 29 & 20 & 15 & 30 & 27 & 24 \\
\hline $\mathrm{Sv}_{\mathrm{O}_{2}}(\%)$ & 83 & 83 & 79 & 81 & 79 & 81 & 80 & 80 \\
\hline $\mathrm{SD}$ & 4 & 5 & 4 & 3 & 3 & 3 & 5 & 6 \\
\hline Qs/Qt (\%) & 16 & 14 & 14 & 12 & 16 & 14 & 14 & 12 \\
\hline SD & 10 & 5 & 9 & 6 & 9 & 11 & 15 & 9 \\
\hline$(\mathrm{A}-\mathrm{a}) \mathrm{DO}_{2}(\mathrm{mmHg})$ & 67 & 79 & 63 & 72 & 63 & 77 & 63 & 81 \\
\hline \multirow[t]{3}{*}{ SD } & 17 & 24 & 34 & 38 & 28 & 26 & 27 & 28 \\
\hline & \multicolumn{8}{|c|}{ With ITI flow of 0.15 liter $/ \mathrm{min}$ per $\mathrm{kg}$} \\
\hline & Cont & ITI & Cont & ITI & Cont & ITI & Cont & ITI with VIB \\
\hline Position & \multicolumn{2}{|c|}{ Carina } & \multicolumn{2}{|c|}{ Bronchus } & \multicolumn{2}{|c|}{ Trachea } & \multicolumn{2}{|c|}{ Carina } \\
\hline$\dot{\mathrm{V}}_{2}(\mathrm{ml} / \mathrm{min})$ & 144 & 147 & 164 & 152 & 156 & 149 & 160 & 165 \\
\hline SD & 15 & 30 & 29 & 27 & 24 & 24 & 31 & 22 \\
\hline $\mathrm{Sv}_{\mathrm{O}_{2}}(\%)$ & 79 & 81 & 78 & 79 & 76 & 77 & 75 & 79 \\
\hline $\mathrm{SD}$ & 3 & 3 & 6 & 6 & 6 & 5 & 5 & 7 \\
\hline Qs/Qt (\%) & 16 & 14 & 12 & 13 & 18 & 16 & 15 & $6\left(^{*}\right)$ \\
\hline SD & 9 & 11 & 9 & 4 & 11 & 12 & 10 & 3 \\
\hline$(\mathrm{A}-\mathrm{a}) \mathrm{DO}_{2}(\mathrm{mmHg})$ & 63 & 77 & 64 & 99 & 85 & 95 & 73 & 62 \\
\hline SD & 28 & 26 & 22 & 21 & 20 & 27 & 35 & 27 \\
\hline
\end{tabular}

* Indicates that value is significantly different from control $(P<0.05)$.

Values are mean $\pm \mathrm{SD}$ of seven experiments.

tially more effective than with the catheter tip in the trachea, 4 $\mathrm{cm}$ from the carina.

The effects of ITI with vibrations. Adding chest vibration at $22 \mathrm{~Hz}$ to ITI delivered at $0.15 \mathrm{liter} / \mathrm{min}$ per $\mathrm{kg}$ near the main carina, substantially increased $\mathrm{CO}_{2}$ elimination between breaths to $162 \pm 34 \mathrm{ml} / \mathrm{min}$. This value is significantly greater than the control $\mathrm{VCO}_{2}$ produced by the $\operatorname{dog}(P<0.05$; Fig. $4 a)$, and is 2.1-3.4-fold higher than when ITI was used alone without vibration. As a result, all dogs stopped breathing completely within $<1$ min from the onset of vibration. $\mathrm{Pa}_{\mathrm{CO}_{2}}$ at the end of 30-40 min of ITI and vibration fell from $68.5 \pm 23.6$ (control) to $47.4 \pm 6.4 \mathrm{mmHg}(P<0.05$; Fig. $4 b)$. Since there was no spontaneous breathing, $\dot{\mathrm{V}}_{\mathrm{E}}$ and $\mathrm{WI} / \mathrm{min}$ were zero and therefore VEI could not be calculated. ITI with vibration was associated with a significant reduction of the shunt (Qs/Qt) from $14.6 \pm 9.9 \%$ to $5.8 \pm 2.8 \%(P<0.05$; Table I). Vibration did not cause systemic hemodynamic changes, but was associated with a $24 \%$ reduction of pulmonary vascular resistance $(P=0.016)$. It should be noted that the respiratory quotient at the end of the vibration period was greater than unity in five of the seven dogs, indicating that steady-state conditions were not yet reached at that time. It is clear, however, that adding high frequency, low amplitude external chest wall vibration to ITI substantially increases gas exchange, to the point where total ventilatory support may be established.

\section{Discussion}

The gas exchange efficiency of ITI was evaluated in an animal model of acute ventilatory failure induced by pentobarbital and pavulon infusion. The hypoventilation that resulted from these substances was associated with higher than normal values of $\mathrm{Pa}_{\mathrm{CO}_{2}}$, but not with hypoxemia, since $\mathrm{O}_{2}$ supplementation was used. ITI increased $\mathrm{CO}_{2}$ elimination, reduced $\mathrm{Pa}_{\mathrm{CO}_{2}}$, minute ventilation, and the work of breathing. The overall effect of ITI was assessed by using the ventilatory efficiency index, a parameter that takes into account the three degrees of freedom in the system: $\mathrm{CO}_{2}$ elimination rate, body $\mathrm{CO}_{2}$ storage, and the amount of mechanical external work produced. VEI was increased 1.9-3.9-fold by ITI without vibration. $\mathrm{O}_{2}$ transport and the cardiovascular system were not affected by ITI alone.

The ventilatory support potential of constant intraairway insufflation has been previously studied in few settings (12, 13). The present study has several new features that should be pointed out:

(a) The animal model of moderate ventilatory failure has not yet been used to study the effectiveness of ITI. This model is particularly relevant to the clinical situation in which a patient may have partial ventilatory insufficiency caused by a pulmonary or neuromusculo-skeletal disorder while maintaining a rudimentary spontaneous breathing effort.

(b) The data analysis. The problem of sorting out the ventilatory contribution of spontaneous breathing with superimposed constant intraairway flow requires special attention. The use of a computer for data acquisition and analysis facilitated the separation of the $\mathrm{CO}_{2}$ elimination to its components. The use of the VEI parameter to evaluate the effects of ITI is new and clearly demonstrates the ITI contribution.

(c) In previous studies, two extremes of flow rates and $\mathrm{O}_{2}$ concentrations were used: constant flow ventilation where high 


\begin{tabular}{|c|c|c|c|c|c|c|c|c|}
\hline & \multicolumn{8}{|c|}{ With catheter tip at the main carina } \\
\hline & Cont & ITI & Cont & ITI & Cont & ITI & Cont & ITI \\
\hline$\dot{\mathrm{V}}_{\mathrm{ITI}}($ liter/min per $\mathrm{kg})$ & \multicolumn{2}{|c|}{0.05} & \multicolumn{2}{|c|}{0.1} & \multicolumn{2}{|c|}{0.15} & \multicolumn{2}{|c|}{0.2} \\
\hline MAP (mmHg) & 128 & 125 & 124 & 122 & 123 & 124 & 121 & 122 \\
\hline SD & 14 & 9 & 10 & 8 & 10 & 8 & 8 & 5 \\
\hline HR (beats/min) & 133 & 129 & 118 & 122 & 119 & 126 & 118 & 124 \\
\hline SD & 22 & 24 & 29 & 32 & 34 & 36 & 34 & 29 \\
\hline CO (liter/min) & 4.1 & 3.9 & 4.0 & 3.9 & 4.0 & 4.1 & 4.1 & 4.0 \\
\hline SD & 0.7 & 0.6 & 0.8 & 0.6 & 0.5 & 0.6 & 1.1 & 1.0 \\
\hline $\operatorname{SVR}\left(\right.$ dyn $\left.\cdot \mathrm{s} \cdot \mathrm{cm}^{-5}\right)$ & 2522 & 2562 & 2481 & 2514 & 2466 & 2397 & 2441 & 2490 \\
\hline SD & 572 & 511 & 595 & 523 & 509 & 496 & 700 & 653 \\
\hline MPP (mmHg) & 18 & 18 & 18 & 16 & 19 & 20 & 20 & 18 \\
\hline SD & 5 & 5 & 3 & 3 & 3 & 3 & 4 & 3 \\
\hline $\operatorname{PVR}\left(\right.$ dyn $\left.\cdot \mathrm{s} \cdot \mathrm{cm}^{-5}\right)$ & 232 & 228 . & 223 & 197 & 213 & 224 & 212 & 208 \\
\hline \multirow[t]{3}{*}{ SD } & 141 & 111 & 137 & 99 & 77 & 91 & 88 & 78 \\
\hline & \multicolumn{8}{|c|}{ With ITI flow of 0.15 liter $/ \mathrm{min}$ per $\mathrm{kg}$} \\
\hline & Cont & ITI & Cont & ITI & Cont & ITI & Cont & ITI with VIB \\
\hline Position & \multicolumn{2}{|c|}{ Carina } & \multicolumn{2}{|c|}{ Bronchus } & \multicolumn{2}{|c|}{ Trachea } & \multicolumn{2}{|c|}{ Carina } \\
\hline MAP (mmHg) & 123 & 124 & 119 & 120 & 121 & 120 & 124 & 125 \\
\hline SD & 10 & 8 & 7 & 4 & 10 & 8 & 11 & 19 \\
\hline HR (beats/min) & 119 & 126 & 118 & 128 & 127 & 117 & 118 & 136 \\
\hline SD & 34 & 36 & 33 & 29 & 34 & 28 & 28 & 27 \\
\hline CO (liter/min) & 4.0 & 4.1 & 4.2 & 3.9 & 3.9 & 3.8 & 3.9 & 3.7 \\
\hline SD & 0.5 & 0.6 & 1.0 & 1.1 & 1.0 & 0.9 & 0.8 & 0.6 \\
\hline $\operatorname{SVR}\left(\operatorname{dyn} \cdot \mathrm{s} \cdot \mathrm{cm}^{-5}\right)$ & 2466 & 2397 & 2314 & 2605 & 2512 & 2595 & 2555 & 2543 \\
\hline SD & 509 & 496 & 581 & 847 & 744 & 725 & 663 & 452 \\
\hline MPP (mmHg) & 19 & 20 & 19 & 18 & 19 & 18 & 21 & 19 \\
\hline SD & 3 & 3 & 4 & 3 & 4 & 4 & 3 & 4 \\
\hline $\operatorname{PVR}\left(\right.$ dyn $\left.\cdot \mathrm{s} \cdot \mathrm{cm}^{-5}\right)$ & 213 & 224 & 201 & 231 & 202 & 224 & 232 & $176\left(^{*}\right)$ \\
\hline SD & 77 & 91 & 62 & 85 & 64 & 93 & 98 & 73 \\
\hline
\end{tabular}

* Value is significantly different from control $(P<0.05)$.

Mean arterial pressure (MAP), heart rate (HR), cardiac output (CO), systemic vascular resistance (SVR), mean pulmonary pressure (MPP), and pulmonary vascular resistance (PVR), during control periods (Cont), ITI, and ITI with vibration (ITI with VIB). Values are mean \pm SD of seven experiments.

flow (i.e., $>1$ liter $/ \mathrm{min}$ per $\mathrm{kg}$ ) of air was used in an attempt to provide total ventilatory support to paralyzed dogs (5); and tracheal insufflation of oxygen where low flow (i.e., $\sim 0.1$ liter/min per $\mathrm{kg}$ ) of oxygen was primarily used to maintain adequate oxygenation $(10,11)$. In the present study, low flow rates (i.e., $0.05-0.2 \mathrm{liter} / \mathrm{min}$ per $\mathrm{kg}$ ) of $40 \%$ oxygen were used as would be feasible in a realistic clinical setting. The gas exchange effects on both $\mathrm{CO}_{2}$ and $\mathrm{O}_{2}$ were evaluated, as well as the effects on spontaneous ventilation and the cardiovascular system.

(d) The effects of catheter tip position were evaluated in previous studies $(8,25)$, but this study is the first, to the best of our knowledge, to compare single mainstem bronchus catheter position with carinal and tracheal ones. This case is clinically relevant, as the practical questions of catheter length and placement have a substantial influence on the gas transport efficiency of ITI. Our data indicate that in terms of gas exchange alone a distal catheter placement is more effective than proximal catheter placement.

(e) We have previously demonstrated the effectiveness of
ITI with vibration in anesthetized, paralyzed animals $(8,22)$. In this study, the hemodynamic and oxygen exchange effects of ITI with vibration were revealed, showing significant reduction of pulmonary vascular resistance and of the shunt.

Mechanisms of gas transport by ITI. The enhancement of $\mathrm{CO}_{2}$ elimination by ITI may be divided into two components. The first is caused by the reduction of the dead space by moving the fresh gas interface from the airway opening to the vicinity of the main carina. To gain full advantage from this mechanism, $\dot{V}_{I T I}$ should be equal to or greater than $\dot{V}_{I} \cdot T_{I} /\left(T_{I}+T_{0}\right)$, where $\dot{V}_{I}$ is the mean inspiratory flow rate, $T_{I}$ is the inspiratory time, and $T_{0}$ is the period from the end of expiration until the beginning of inspiration. This mechanism is important when $V_{T}$ is low and the breathing frequency is high.

The second mechanism of gas transport is directly caused by the ITI flow and functions to remove $\mathrm{CO}_{2}$ from the airways during the period of breath hold from the end of exhalation until the onset of the next inhalation (Fig. $2 b$ ). This mechanism is dominant when $V_{T}$ is relatively large and the interval between breaths is long. Fig. 3 shows the time-averaged $\mathrm{CO}_{2}$ 
removal rate between breaths. Despite the statistical significance of the increased removal with ITI $>0.05 \mathrm{liter} / \mathrm{min}$ per $\mathrm{kg}$, the magnitude of the increase with increasing ITI flow is marginal. On the other hand, changes of the catheter tip position in the airways were associated with substantial improvement when the tip was advanced further into the airways. These observations are compatible with predictions of Nahum et al. (19) on the momentum transfer and penetration depth of jets into airways. Cardiogenic oscillations (20), molecular diffusion, and turbulence in the vicinity of the jet determine the position of the stationary front (21) and its distance from the catheter tip where transport by convection occurs. The factors that determine this type of gas transport are not completely understood. The fact that ITI via a single catheter inserted into a mainstem bronchus was equally or more effective than when the tip position was near the carina requires invoking yet additional mechanisms such as cardiogenic-induced interlung flows.

Superimposing vibration on ITI has previously been shown to increase its efficiency, to the point where it may be used for complete ventilatory support $(8,9,22)$. The mechanisms of this augmentation of gas exchange are not clear. Interlung flows, induced by the out of phase motion of the mediastinum relative to the chest wall may play an important role in this mode of ventilation (23).

ITI with vibration caused a significant reduction in shunt and in pulmonary vascular resistance. The effect on shunt may reflect increased overall alveolar ventilation with diminished extent of hypoventilated areas and improved relative distribution of ventilation-perfusion (26). The reduction in pulmonary artery resistance may be caused by the elimination of tidal breaths, to a mechanical effect on the pulmonary vascular endothelium inducing release of vasodilating agents such as prostacycline (24), or to elimination of hypoxic vasoconstriction in those lung regions that were significantly hypoventilated.

Conclusions. This study clearly shows that ITI improves $\mathrm{CO}_{2}$ transport during partial ventilatory failure in dogs with normal lungs. A flow rate of $0.1-0.15 \mathrm{liter} / \mathrm{min}$ per $\mathrm{kg}$ delivered via a narrow catheter placed near or beyond the main carina was found to be optimal. Superimposing high frequency external chest wall vibration further increased gas exchange and provided complete ventilatory support. The potential of ITI and, when needed, ITI with vibration, to provide an alternative mode of ventilatory support for patients with predominant hypoventilation caused by pulmonary or neuromuscular disorders should be investigated. Such patients, particularly those who do not need an endotracheal tube for frequent bronchial suctioning, may benefit from this new method that requires only a narrow intraairway catheter, if it is proved efficient in patients as well as in the experiments of this study.

\section{Acknowledgments}

We acknowledge the encouragement and support of Prof. Edward Brunner. Professors S. Glisson, R. Harrison, and D. W. Cugell provided equipment and advice that were essential for the project. Ms. Christine Craig participated and assisted in the experimental procedures. Ms. Adriana Contreras provided secretarial support.

This study was supported by the Department of Anesthesia, North- western University, and National Institutes of Health grants HL-41 126 and HL-35440.

\section{References}

1. Drinker, P., and L. A. Shaw. 1929. An apparatus for the prolonged administration of artificial respiration. I. A design for adults and children. J. Clin. Invest. 7:229-243.

2. Hayek, Z., A. Peliowski, A. Ryan, R. Jones, and N. Finer. 1986. External high-frequency oscillation in cats. Experience in the normal and after lung lavage. Am. Rev. Respir. Dis. 133:630-634.

3. Plum, F., and G. D. Whedon. 1951. The rapid-rocking bed: its effect on the ventilation of poliomyelitis patients with respiratory paralysis. N. Engl. J. Med. 245:235-241.

4. Chang, H. K. 1984. Mechanisms of gas transport during ventilation by high-frequency oscillation. J. Appl. Physiol. 56:553-562.

5. Lehnert, B. E., G. Oberdoster, and A. S. Slutsky. 1982. Constant flow ventilation in apneic dogs. J. Appl. Physiol. 53:483-489.

6. Carlon, G., S. Miodownik, C. Ray, Jr., and R. C. Kahn. 1981. Technical aspects and clinical implications of high frequency jet ventilation with a solenoid valve. Crit. Care. Med. 9:47-63.

7. Villar, J., B. Winston, and A. S. Slutsky. 1990. Non-conventional techniques of ventilatory support. Critical Care Clin. 6:579-603.

8. Bitterman, H., D. H. Kerem, Y. Shabtai, N. Gavriely, and Y. Palti. 1983. Respiration maintained by externally applied vibration and tracheal insufflation in the cat. Anesth. Analg. 62:33-38.

9. Gavriely, N., and Y. Shabtai. 1987. The effect of tracheal bias flow on gas exchange during high-frequency chest percussion. J. Appl. Physiol. 63:303-308.

10. Slutsky, A. S., J. Watson, D. E. Leith, and R. Brown. 1985. Tracheal insufflation of $\mathrm{O}_{2}$ ( TRIO) at low flow rates sustains life for several hours. Anesthesiology. 63:278-286.

11. Reed, J. P., J. P. Kemph, W. Hamelbery, F. A. Hitchcock, and J. Jacoby. 1954. Studies with transtracheal artificial respiration. Anesthesiology. 15:28-41.

12. Bergofsky, E. H., and A. N. Hurewitz. 1989. Airway insufflation: physiologic effects on acute and chronic gas exchange in humans. Am. Rev. Respir. Dis. 140:885-890.

13. Couser, J. I., Jr., and B. J. Make. 1989. Transtracheal oxygen decreases inspired minute ventilation Am. Rev. Respir. Dis. 139:627-631.

14. Altman, P. L., and D. S. Dittmer. 1971. Biological Handbooks: Respiration and Circulation. Federation of American Societies for Experimental Biology, Bethesda, MD. pp. 179-184.

15. Alderson, A. M., and J. MacLagan. 1964. The action of decamethonium and tubocurarine on the respiratory and limb muscle of the cat. J. Physiol. (Camb.). 173:38-56.

16. Lee, C., N. Durant, N. Nguen, B. Tran, and R. Katz. 1982. Comparative neuromuscular pharmacology of the diaphragm and the tibialis anterior. Anesthesiology. 57:A282 (Abstr.)

17. Gilman, G. A., T. W. Rall, A. S. Nies, and P. Taylor. 1990. Goodman and Gilman's the Pharmacological Basis of Therapeutics. 8th ed. Pergamon Press. p. 175.

18. Gilman, G. A., T. W. Rall, A. S. Niles, and P. Taylor. 1990. Goodman and Gilman's The Pharmacological Basis of Therapeutics. 8th Ed. Pergamon Press. $p$. 360.

19. Nahum, A., J. I. Sznajder, J. Solway, L. D. H. Wood, and P. Schumacker. 1988. Pressure, flow and density relationships in airway models during constantflow ventilation. J. Appl. Physiol. 64:2066-2073.

20. Burwen, D. R., J. Watson, R. Brown, M. Josa, and A. S. Slutsky. 1986. Effect of cardiogenic oscillations on gas mixing during tracheal insufflation of oxygen. J. Appl. Physiol. 60:965-971.

21. Engel, L. A., and P. T. Macklem. 1977. Gas mixing and distribution in the lung. In Respiratory Physiology II. J. G. Widdicombe, editor. Int. Rev. Physiol. Ser. Baltimore MD. 14:38-82.

22. Shabtai, Y., and N. Gavriely. 1991. Frequency and amplitude effects during high frequency vibration ventilation in dogs. J. Appl. Physiol. 66:11271135.

23. Zicherman, Y., A. Shavit, and N. Gavriely. 1990. Intra-lung air flow induced by externally applied vibrations. First World Congress of Biomechanics, La Jolla, CA. PII:166. (Abstr.)

24. Piper, P., and J. Vane. 1971. The release of prostaglandins from lung and other tissues. Ann. NY Acad. Sci. 180:363-385.

25. Slutsky, A. S., and A. S. Menon. 1987. Catheter position and blood gases during constant-flow ventilation. J. Appl. Physiol. 62:513-519.

26. Vettermann, J., V. Brusasco, and K. Rehder. 1988. Gas exchange and intrapulmonary distribution of ventilation during continuous-flow ventilation. $J$. Appl. Physiol. 64:1864-1869. 